\title{
A toxicity-based method for evaluating safety of reclaimed water for environmental reuses
}

\author{
Jianying $\mathrm{Xu}^{1}$, Chuntao Zhao ${ }^{1,2}$, Dongbin $\mathrm{Wei}^{2, *}$, Yuguo $\mathrm{Du}^{2}$ \\ 1. College of Resource Environment and Tourism, Capital Normal University, Beijing 100048, China. E-mail: xu-jianying@163.com \\ 2. State Key Laboratory of Environmental Chemistry and Ecotoxicology, Research Center for Eco-Environmental Sciences, \\ Chinese Academy of Sciences, Beijing 100085, China
}

\section{A R T I C L E I N F O}

Article history:

Received 22 November 2013

Revised 4 December 2013

Accepted 8 December 2013

Available online 3 August 2014

Keywords:

Toxicity

Safety

Water quality

Reclaimed water

\begin{abstract}
A B S T R A C T
A large quantity of toxic chemical pollutants possibly remains in reclaimed water due to the limited removal efficiency in traditional reclamation processes. It is not enough to guarantee the safety of reclaimed water using conventional water quality criteria. An integrated assessment method based on toxicity test is necessary to vividly depict the safety of reclaimed water for reuse. A toxicity test battery consisting of lethality, genotoxicity and endocrine disrupting effect was designed to screen the multiple biological effects of residual toxic chemicals in reclaimed water. The toxicity results of reclaimed water were converted into the equivalent concentrations of the corresponding positive reference substances (EQC). Simultaneously, the predicted no-effect concentration (PNEC) of each positive reference substance was obtained by analyzing the species sensitivity distribution (SSD) of toxicity data. An index "toxicity score" was proposed and valued as 1, 2, 3, or 4 depending on the ratio of the corresponding EQC to PNEC. For vividly ranking the safety of reclaimed water, an integrated assessment index "toxicity rank" was proposed, which was classified into A, B, C, or D rank with A being the safest. The proposed method was proved to be effective in evaluating reclaimed water samples in case studies.
\end{abstract}

C 2014 The Research Center for Eco-Environmental Sciences, Chinese Academy of Sciences. Published by Elsevier B.V.

\section{Introduction}

Many countries all over the world are facing serious freshwater resource crisis due to the rapid economical development and extreme climate. Reclamation and reuse of wastewater offer an effective way of conserving limited high-quality freshwater supplies while helping to meet the demands for water. However, the safety of reclaimed water becomes bone of contention from the just beginning of wastewater reuse. Toxic chemicals are one of dominant hazardous components in wastewater while the conventional reclamation treatment processes cannot remove them thoroughly. Therefore, the residual toxic chemicals in reclaimed water would accumulate and cause potential risk on organism even human health during long term reuse practices (Asano et al., 2007). Traditionally, the water quality is judged by some individual concentration limits of priority chemicals and integral parameters, such as chemical oxygen demand (COD), biochemical oxygen demand (BOD 5 ), and so on. Since the concentration limits involved in water quality criteria cannot cover all chemicals in ambient water matrix, the concentration analysis alone cannot sufficiently evaluate the safety of water sample. Moreover, synergistic or antagonistic interactive effects among the co-existing multiple chemicals in ambient water could not be ignored (Juvonen et al., 2000). Therefore, to some extent, it is insufficient to guarantee water quality using conventional water quality criteria. In the recent decades, toxicity tests have been developed as useful tools not

\footnotetext{
* Corresponding author. E-mail address: weidb@rcees.ac.cn (Dongbin Wei).
} 
only for evaluating the biological effect of individual chemical, but also for integrating the effect of all the bio-available contaminants and of their interaction as a whole (Hernándo et al., 2005). For example, the whole effluent toxicity testing was formalized by the U.S. Environmental Protection Agency (USEPA, 1991), with the intent to identify, characterize, and eliminate toxic effects of discharges on aquatic resources (USEPA, 1996).

Although it is feasible for toxicity tests to measure the adverse effects of chemical pollutants individually even jointly (Wei et al., 2004), the expression of toxicity results become an important issue especially for mixture of multiple chemicals even for ambient water samples. In the early stage, mortality was usually used to evaluate water quality (Vindimian et al., 1999; Liu et al., 2007). Toxicity unit was another index (Jin et al., 1999), which was defined as the inverse of the EC50 values, to classify the water sample according to toxicity classification system (Mantis et al., 2005). In addition, the pT-method was developed to evaluate the toxic effects of wastewaters (Krebs, 2005). Simply, the water sample was geometrically diluted with a factor of two and tested with standardized bioassays. Its toxic status was equated with the first dilution stage at which the effluent no longer observed toxicity. The PEEP (Potential Ecotoxic Effects Probe) index was a simple effects-based hazard assessment scheme to compare the toxic potential of a series of wastewaters discharging to a common receiving aquatic ecosystem (Blaise and Ferard, 2005). The PEEP index ranges from 0 to 10. The higher an effluent's PEEP index value, the more potentially hazardous it is toward aquatic biota.

In order to roundly evaluate the potential risk, single toxicity test result maybe not enough because the various chemicals exhibit different biological effects. Therefore, toxicity test battery composed of different biological effects to complement physicochemical analyses has been recommended (Bispo et al., 1999; Békaert et al., 1999). For example, a toxicity test set with three commonly recommended aquatic toxicity tests: acute fish lethal test, acute daphnia immobilization test and chronic algae growth inhibition test were selected to evaluate the toxicity of water sample (Férard and Ferrari, 2005). Since the endpoints for different toxicity tests are various, it is hard to establish a reasonable and simple assessment index to characterize the hazards of pollutants on aquatic organism. In some of previous studies, a variation of assessment indices such as pesticide toxic index (PTI), risk-based scoring system (Kimerle et al., 1997; Personne et al., 2003) was developed to protect freshwater aquatic organism. However, the PTI method ignored the interaction (synergism, antagonism) among the coexisted chemicals in the environment (Munn and Gilliom, 2001), and the risk-based scoring system did not extrapolate the long-term hazard of pollutants to aquatic organism. Recently, Wei et al. (2006) proposed a biological safety evaluation method on the basis of the risk extrapolation of chemical pollutants to overcome those limitations of previous toxicity classification systems. As a whole, most of reported toxicity test sets for assessing water quality were composed of acute or chronic toxicity tests at population level, while scarcely contained any other specific toxicity effects, such as genotoxicity, endocrine disrupting effect and so on. In fact, besides the compounds with lethality, a large number of chemicals with genotoxic and endocrine disrupting effects have been detected within environmental matrices (Quirós et al., 2005). Some assays such as Ames test, SOS/umu test, and micronucleus test were used to measure the genotoxicity of pollutants in surface water and wastewater (Mathur et al., 2007). Simultaneously, two-hybrid yeast test was frequently used to evaluate the endocrine disrupting effects of environmental samples (Ma et al., 2007).

Therefore, how to reasonably evaluate the potential threats of reclaimed water on organism and human health becomes a concomitant issue. The objectives of this work were to compose a toxicity test battery covering three different biological effects, to establish safety assessment method based on toxicity tests, and to evaluate the adverse effects of reclaimed water on aquatic organism.

\section{Composition of toxicity test battery}

It is reported that municipal wastewater treatment plants (WWTPs) are the main sources of toxic chemicals input into aquatic environments (Auriol et al., 2006). Most of early effluent monitoring focused on nutrients, metals, and organic compounds of industrial origin (Ying et al., 2004). With the rapid development of analytical detection techniques, more and more pollutants with various biological effects, have been detected within wastewater and reclaimed water. Some reports showed that quinolone antibiotics reached $123 \mu \mathrm{g} / \mathrm{L}$ (ofloxacin) in wastewater samples (Michael et al., 2013). It has been proved that quinolones have strong genotoxicity (Li et al., 2014). In addition, the detection on the chemicals with endocrine disrupting effects in wastewaters has drawn much attention during the past decade. Estrogenic steroid hormones have been found in WWTP discharges in Europe, the United States, Canada, and Japan at concentrations as high as $64 \mathrm{ng} / \mathrm{L} \mathrm{E2,} 82 \mathrm{ng} / \mathrm{L} \mathrm{E1}$, and 18 ng/L E3 (Ying et al., 2002). Chang et al. (2008) analyzed the residual androgens and progestogens in the wastewater samples from Japan. The concentrations of nonylphenol, octylphenol and bisphenol A in a WWTP in Beijing, China, were 13.4, 1.4 and $89.0 \mu \mathrm{g} / \mathrm{L}$ in the influent and $0.41,0.11$ and $0.32 \mu \mathrm{g} / \mathrm{L}$ in the effluent, respectively (Sun et al., 2008).

Recently there are some reports about evaluation of water quality or efficiency of treatment units using lethality tests. Zha and Wang (2005) assessed technological feasibility for reuse of secondary effluent from WWTP using morality of larval medaka. The $96 \mathrm{hr}$ LC $_{50}$ values for raw wastewater, secondary effluent, ultrafiltration (UF) effluent, and microfiltration (MF) effluent were $33.7 \%, 62.9 \%, 60.0 \%$, and $64.4 \%$ concentrations, respectively (Zha et al., 2005). The removal ability of anoxic-oxic (A/O) process in WWTP was evaluated by lethality (mortality of zebrafish) and genotoxicity (micronucleus and comet assays). Results showed that, in A/O process, the lethality was completely removed, while the genotoxicity increased (Zhang et al., 2013). In addition, lethality and genotoxicity tests were used to measure the treatment performance of conventional wastewater treatment processes anaerobic-anoxic-oxic $\left(\mathrm{A}^{2} \mathrm{O}\right)$ and reclamation processes (ultrafiltration, ozonation, chlorination). The toxicity tests indicated that both the acute toxicity and genotoxicity had great decrease after the $\mathrm{A}^{2} \mathrm{O}$ process. However, advanced chemical reclamation processes such as ozonation and chlorination could possibly cause toxicity increase again (Wei et al., 2012).

In addition, some researchers determined the estrogenic activity of WWTP effluents in Japan (5-15 ng/L EEQ (estradiol equivalent concentration)), the United States (44-151 ng/L EEQ), Sweden (<0.1-15 ng/L EEQ), and Switzerland (0.1-90 ng/L EEQ), using the yeast estrogen screen (YES) assay (Matsui et al., 2000; Tilton et al., 2002; Svenson et al., 2003; Rutishauser et al., 2004). Estrogenic potencies of the effluents from WWTPs in Beijing City were estimated by using a human estrogen receptor recombinant yeast assay. Estrogenic activity of industrial wastewaters was found to range from 0.1 to $13.3 \mathrm{ng} / \mathrm{L}$ EEQ and decreased to the range of 0.03-1.6 ng/L EEQ after secondary treatment. Estrogenic activity in WWTP influent ranged from 0.3 to $1.7 \mathrm{ng} / \mathrm{L}$ EEQ and decreased to the range of 0.05-0.5 ng/L EEQ after secondary treatment (Ma et al., 2007). 
Based on the above discussion, it can be concluded that lethality, genotoxicity and endocrine disrupting effects could represent the major biological effects of those frequently detected toxic chemicals in wastewater and reclaimed water. Therefore, in this study, three typical toxicity effects, lethality, genotoxicity, and endocrine disrupting effects should be involved in the test battery to thoroughly measure the safety of reclaimed water.

\section{Optimization on toxicity tests}

It is well known that there are many in vitro and in vivo methods which have been recommended by ISO (International Organization for Standardization), OECD (Organization for Economic Co-operation and Development), USEPA (United States Environmental Protection Agency), and other international or national authoritative organizations, which can be used to measure the lethality (USEPA, 2002), genotoxicity (ISO, 2000), and endocrine disrupting effects (OECD, 2012). However, most of the methods are suitable for measuring the toxicity of individual chemical, but less for environmental samples containing unknown complex components. Considering that the aim of this study is to conveniently and rapidly screen the safety of reclaimed water, three bioassays including photobacterium luminescence inhibition test, SOS/umu test, and human estrogen receptor recombinant yeast assay, were selected to measure the lethality, genotoxicity and endocrine disrupting effects, respectively.

\subsection{Preparation of test samples}

Reclaimed water sample (2 L) was flew through two preconditioned Waters Oasis HLB and C18 cartridges using a solid phase extraction apparatus at $10 \mathrm{~mL} / \mathrm{min}$. Ten milliliters of acetone and dichloromethane was respectively pumped into each cartridge at $2.0 \mathrm{~mL} / \mathrm{min}$ for elution; the eluates were mixed in a scaled centrifuge tube, and evaporated to $200 \mu \mathrm{L}$ under nitrogen gas purge at $300 \mathrm{~mL} / \mathrm{min}$. The residues were carefully added on a column containing $10 \mathrm{~g}$ silica $(60-200 \mathrm{~mm}$, $60 \AA$, Acros Organics, NJ, USA) and $10 \mathrm{~g} \mathrm{Al}_{2} \mathrm{O}_{3}$ (50-200 mm, Acros Organics, NJ, USA). The column was eluted with $15 \mathrm{~mL}$ hexane (HPLC Grade; Fisher, NJ, USA) to yield a nonpolar fraction, followed by $70 \mathrm{~mL}$ mixture of hexane/ $\mathrm{CH}_{2} \mathrm{Cl}_{2}(7: 3, \mathrm{~V} / \mathrm{V})$ to obtain a polar fraction. The two fractions were mixed and evaporated to $2 \mathrm{~mL}$ using a rotary-evaporator followed by blowing to dryness with a gentle nitrogen flow. The residues were dissolved in $0.2 \mathrm{~mL}$ dimethyl sulfoxide (DMSO). The concentrated solution would be used to prepare exposure solutions for three toxicity tests. For each test, a series of gradients of reclaimed water sample were exposed to obtain dose-response curve. Simultaneously, mercury chloride $\left(\mathrm{Hg}^{2+}\right)$, 4-nitroquinoline-1-oxide (4-NQO), and estradiol (E2) were set as positive controls in lethality, genotoxicity and endocrine disrupting tests, respectively. The solvent control ( $0.1 \%$ of DMSO) was set in each toxicity test as well. All three toxicity tests were performed in triplicate.

\subsection{Lethality test}

The Photobacterium phosphoreum toxicity test quantifies the decrease in light emission after exposure to toxic pollutants (SEPA, 1995). The test instrument DXY-2 Model Toxicity
Analyzer was made by the Institute of Soil Science, Chinese Academy of Sciences, Nanjing, China. The bacteria P. phosphoreum strain was also provided as a freeze-dried powder by the same institute. Prior to toxicity tests, the freeze-dried powder of P. phosphoreum strain was reactivated and continuously cultured for three generations at $20^{\circ} \mathrm{C}$ with continuous mixing. A $1 \mathrm{~mL}$ aliquot of the log-phase bacterial suspension was diluted with $50 \mathrm{~mL}$ culture suspension and stirred for $1 \mathrm{hr}$. Subsequently, $1.4 \mathrm{~mL}$ of each treated sample and $200 \mu \mathrm{L}$ of bacterial suspensions were added to $0.4 \mathrm{~mL}$ of $15 \% \mathrm{NaCl}$ solution. The decrease in bioluminescence indicated a toxic effect by water sample after a 15 min exposure at $(20 \pm 1)^{\circ} \mathrm{C}$. The bioluminescence inhibition ratio was calculated according to the method described in GB/ T15441-1995 (SEPA, 1995).

\subsection{Genotoxicity test}

The genotoxicity of reclaimed water sample was determined with the SOS/umu test (ISO, 2000; Oda et al., 1985). Salmonella typhimurium TA1535/pSK1002 in the SOS/umu test carrying an umuC-lacZ fusion gene on multicopy plasmid pSK1002 was obtained from Prof. Y. Oda (Osaka Prefectural Institute of Public Health, Japan). Briefly, the overnight bacterial culture was diluted 10 times with fresh TGA medium and incubated at $37^{\circ} \mathrm{C}$ for $1.5 \mathrm{hr}$ with shaking $(130 \mathrm{r} / \mathrm{min})$ until the bacteria reached the exponential growth phase. The test was performed on a microplate with the incubation mixture consisting of $180 \mu \mathrm{L}$ concentrated water sample, $20 \mu \mathrm{L}$ of $10 \times$ TGA and $70 \mu \mathrm{L}$ of bacterial culture (content of DMSO was ca. 1\%). The microplate was incubated at $37^{\circ} \mathrm{C}$ for $2 \mathrm{hr}$ with shaking (130 r/min); the incubation mixture was then diluted 10 times with fresh TGA medium and incubated for an additional $2 \mathrm{hr}$. The absorbance at 600 and $420 \mathrm{~nm}$ was measured with a microplate reader (Tecan, Mannedorf, Switzerland). The bacterial growth factor and induction ratio were calculated according to the method described in ISO 13829 (ISO, 2000).

\subsection{Endocrine disrupting effect test}

A test based on recombinant yeast strain (Saccharomyces cerevisiae) was applied to screen the endocrine disrupting effect (Rehmann et al., 1999; Wang et al., 2003; Ma et al., 2007). Yeast strain was stored at $-80^{\circ} \mathrm{C}$ and pre-incubated at $30^{\circ} \mathrm{C}, 150 \mathrm{r} / \mathrm{min}$ in Erlenmeyer flasks. After $24 \mathrm{hr}$, yeast suspension with optical density at $600 \mathrm{~nm}\left(\mathrm{OD}_{600}\right)$ reached 1.0-1.5. An aliquot of $50 \mu \mathrm{L}$ concentrated reclaimed water sample was added into $1.5 \mathrm{~mL}$ Eppendorf tubes containing $950 \mu \mathrm{L}$ yeast suspension and carefully mixed. The $200 \mu \mathrm{L}$ of the test culture was transferred into 96-well microplate and incubated at $30^{\circ} \mathrm{C}, 600 \mathrm{r} / \mathrm{min}$. Cell density was determined by measuring $\mathrm{OD}_{600}$ after $2 \mathrm{hr}$. The $150 \mu \mathrm{L}$ of culture was removed from each well. After addition of $120 \mu \mathrm{L}$ buffer and $20 \mu \mathrm{L}$ chloroform, the samples were mixed for 10 and $20 \mathrm{~min}$, respectively. The coloring reaction was started by $40 \mu \mathrm{L}$ onitrophenyl- $\beta$-D-galactopyranoside (ONPG, $4 \mathrm{~g} / \mathrm{L}$ in buffer), and reacted in $30 \mathrm{~min}$ for $\mathrm{E} 2,120 \mathrm{~min}$ for others and quenched by $100 \mu \mathrm{L} \mathrm{Na}_{2} \mathrm{CO}_{3}(1 \mathrm{~mol} / \mathrm{L})$. $\mathrm{OD}_{420}$ of supernatants was recorded by a microplate reader (Tecan, Switzerland). The $\beta$-galactosidase activity was calculated according to the references (Wang et al., 2003; Huber et al., 2004). 


\subsection{Description of toxicity results}

For each toxicity test, two dose-response curves could be obtained, one was of positive reference substance, and the other was of tested reclaimed water sample. Take the genotoxicity test as an example, for positive reference substance 4-NQO, the $X$-axis of the dose-response curve is represented by the absolute mass of 4-NQO ( $\mu \mathrm{g})$ in the test well, in lieu of concentration (e.g., mg/L). For tested water sample, the $\mathrm{X}$-axis is represented by the converted volume of the original water sample (L) in the test well, in lieu of concentration factor. The $\mathrm{Y}$-axis is represented by the induction ratio. The slope of the dose-response curve for 4-NQO is marked as $\mathrm{S}_{4-\mathrm{NQO}}$, and that for the water sample is marked as $\mathrm{S}_{\text {Sample. }}$ Therefore, the genotoxicity effect of water sample could be expressed as the equivalent concentration of $4-\mathrm{NQO}\left(\mathrm{EQC}_{4-\mathrm{NQO}}, \mu \mathrm{g} / \mathrm{L}\right)$, defined as the ratio of $\mathrm{S}_{\text {Sample }}$ to $\mathrm{S}_{4-\mathrm{NQO}}$. With this parameter, the integrated genotoxicity effect of those chemicals in water sample would be described with the equivalent concentration of 4-NQO according to their equal toxicity effect. Higher $\mathrm{EQC}_{4-\mathrm{NQO}}$ of water sample represents a stronger toxicity effect. Similarly, $\mathrm{EQC}_{\mathrm{Hg}}^{2+}$ and $\mathrm{EQC}_{\mathrm{E}_{2}}$ were corresponding toxicity equivalent concentrations for acute toxicity and endocrine disrupting effects.

\section{Derivation of PNECs}

Since the toxicity test results of reclaimed water sample were converted into the equivalent concentration of positive reference substances (EQCs), the subsequent safety assessment on reclaimed water could be conducted as the similar method proposed for the individual chemical in ambient water (ECETOC, 1993; Wagner and Lokke, 1991). Among these methods, the most popular one is the predicted environmental concentration (PEC)/predicted no-effect concentration (PNEC) ratio method (Directive EEC/93/67) recommended by the Commission of European Communities (EEC, 1993). The PEC can be measured or estimated from different fate and exposure models; it is relatively easy for some individual chemicals. In this study, the PEC value of reclaimed water could be surrogated by the equivalent concentration of positive reference substance (EQC). The PNEC is usually estimated by an extrapolation of ecotoxicity data. However, the PNEC value derived from different sources of toxicity data or calculated with different methods had large variation. Since each chemical has multiple mode-of-actions even to each test species, the selection of toxicity data from different mode-of-actions would heavily affect the PNEC value. In this study, in order to obtain reliable PNEC value, the sensitive mode-of-action for each positive reference substance was considered. That is, the PNEC of $\mathrm{Hg}^{2+}$ should be calculated with chronic lethal toxicity data, PNEC of 4-NQO should be calculated with the genotoxicity data, and PNEC of E2 should be calculated with endocrine disrupting data, respectively.

There are usually two basic methods for deriving PNEC of individual chemical (EC, 2003). A simple deterministic approach uses a critical parameter of the available toxicity data (the lowest is $\mathrm{LC}_{50}$ or NOEC) and divides it by an assessment factors (AF), usually in the range of 1-1000 (EC, 2003). However, these methods are also limited because assessment factors are somewhat arbitrary and uncertainty of the PNEC is generally not quantified (Chapman et al., 1998). Another method for deriving the PNEC, species sensitivity distribution (SSD), is based on the assumption that variation in chemical sensitivity among species can be described by assessment of the distributions of toxicity data (Aldenberg and Jaworska, 2000; Posthuma et al., 2002). After estimation of its parameters, the distribution can be used to predict a concentration value which does not exceed the NOEC for a predefined percentage of the species, such as $95 \%$. The SSD method can produce more robust PNEC, but adequate chronic toxicity data is only available for select taxonomic groups, and is lacking for most new and existing substances (Sijm et al., 2001).

\subsection{PNEC of $\mathrm{Hg}^{2+}$}

In total, 40 chronic toxicity data for inorganic mercury $\left(\mathrm{Hg}^{2+}\right)$ was collected. The NOECs of $\mathrm{Hg}^{2+}$ ranged from 0.25 to $2250 \mu \mathrm{g} / \mathrm{L}$ for all tested species. These NOEC values were tested with 34 aquatic species belonging to five taxonomic groups, i.e., fish, crustaceans, protozoa, mollusca, and alga. The PNEC of $\mathrm{Hg}^{2+}$ was deduced with SSD method. First, the geometric means of NOECs for each test species were calculated. Second, the data were then sorted and the cumulative probability $\left(P_{c}\right)$ for each species was calculated as the following equation:

$P_{c}=i /(n+1)$

where, $i$ is the rank of a species in the data series, and $n$ is the total number of examined species (Schuler et al., 2008). Third, a log-logistic SSD curve was constructed using the logarithmic NOEC values as the $X$-axis and the cumulative probability as the Y-axis, to describe the distribution of toxicity data. Fourth, the PNEC was determined by extrapolation from the curve. The parameters such as the adjusted coefficient of determination $\left(R^{2}\right)$ and residual sum of squares (RSS) can be used to compare the suitability of models for given data and determine the optimum model. The fitted SSD curve of $\mathrm{Hg}^{2+}$ is shown in Fig. 1a. The extrapolated PNEC of $\mathrm{Hg}^{2+}$, expressed as $\mathrm{PNEC}_{\mathrm{Hg}}^{2+}$, is $0.18 \mu \mathrm{g} / \mathrm{L}$.

\subsection{PNEC of 4-NQO}

4-Nitroquinoline-1-oxide (4-NQO), a water soluble quinoline derivative which was initially developed as a chemotherapeutic agent (Nakahara et al., 1957), has been shown to produce sister chromatid cohesion in mice (Steidler et al., 1984). Although it is not a known, naturally occurring carcinogen, it has been used as an internal standard in determining the carcinogenic potential of compounds (Sato et al., 1991). 4-NQO causes DNA adduct formation resulting in adenosine substitution for guanidine. In this study, 4-NQO was used as positive reference substance for genotoxicity test, so the genotoxicity data, carcinogenesis data, and mutatogenesis data were collected for 4-NQO. In total, 12 NOEC data of genotoxicity (carcinogenesis) in fish, mice and cell lines following exposure to 4-NQO were collected. The NOEC values cover a relatively wide range, from 1.1 to $2 \times 10^{5} \mu \mathrm{g} / \mathrm{L}$. The SSD for 4-NQO was constructed by fitting a cumulative probability distribution to 12 NOECs. The fitted SSD curve of 

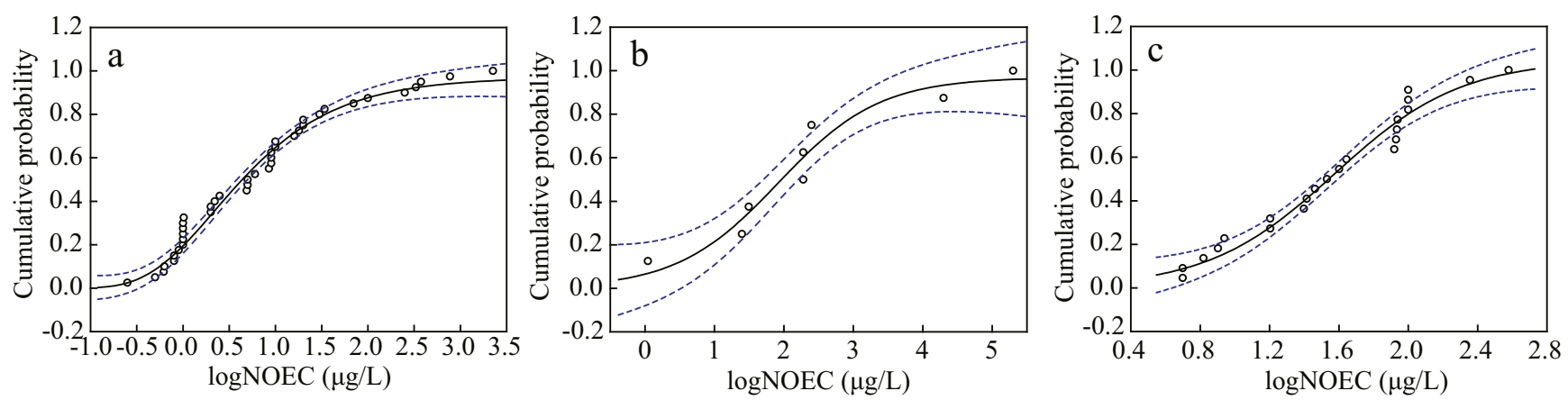

Fig. 1 - Species sensitivity distribution curves of three positive reference substances. (a) $\mathrm{Hg}^{2+}$, (b) 4-NQO, (c) E2.

4-NQO is shown in Fig. 1b. The resulting PNEC for 4-NQO, expressed as $\mathrm{PNEC}_{4-\mathrm{NQO}}$, is $0.64 \mu \mathrm{g} / \mathrm{L}$.

\subsection{PNEC of E2}

The critical endpoint for the positive reference E2 reproductive effect is consistent with its mode of action, i.e., binding to estrogen receptors. In total, 22 NOEC data of reproductive effects in nine fish species following exposure to E2 were collected. The NOECs or species other than fish range from 0.5 to $3100 \mu \mathrm{g} / \mathrm{L}$. Comparison of NOECs across taxa demonstrates no overlap between invertebrates and fish. Furthermore, no single statistical model is a good fit for the combined data. Two distinct models, one for invertebrates and one for fish, best fit the data, indicating a clear difference between taxa, with fish being more sensitive. Therefore, only the fish data were used to construct the SSD for E2 from which the PNEC was derived. The SSD for E2 was constructed by fitting a distribution to 22 NOECs from 19 reproduction studies in 8 fish species. The fitted SSD curve of E2 is shown in Fig. 1c. The resulting PNEC for E2, expressed as $\mathrm{PNEC}_{\mathrm{E}_{2}}$, is $2 \mathrm{ng} / \mathrm{L}$.

\section{Proposal of assessment indices}

\subsection{Proposal and determination of toxicity score}

For each reclaimed water sample, a series of solutions with different concentrations were prepared for three toxicity tests. The toxicity test result of reclaimed water for each toxicity test was converted into the equivalent concentration of corresponding positive reference substance. In addition, considering the various reuse objectives of reclaimed water, the requirements for water quality were quite different. In this study, we focused on the environmental and recreational reuses of reclaimed water, which includes three of main uses: (1) natural and man-made wetlands, (2) recreational and esthetic impoundments, (3) stream augmentation scenic and stream augmentation (USEPA, 2004). Generally, the reclaimed water was partly or fully supplemented as water source for environmental reuse. Therefore, the water quality of reclaimed water has to meet the demand for protecting the safety of organisms in aquatic system. As mentioned above, the potential risk of reclaimed water on aquatic organisms could be depicted by the ratio of three EQCs of positive reference substances to their corresponding PNECs. Therefore, in this study, for easily describing the intensity of toxicity effect and comparing the toxicity among different test species, a novel index "toxicity score" was proposed. The toxicity score includes 1, 2, 3, and 4; the toxicity effect increases as the toxicity score changing from 1 to 4 . The valuation approach for toxicity score is shown in Fig. 2. Take the genotoxicity test as an example, if the ratio of $\mathrm{EQC}_{4-\mathrm{NQO}}$ to $\mathrm{PNEC}_{4-\mathrm{NQO}}$ is less than 1, the toxicity score is valued as 1 . If the ratio is more than 1 while less than 10 , the toxicity score is valued as 2. If the ratio is more than 10 while less than 100 , the toxicity score is valued as 3 . If the ratio is more than 100 , the toxicity score is valued as 4 .

\begin{tabular}{|l|c|c|c|c|}
\hline & \multicolumn{2}{|c}{ High $\leftarrow$ Toxicity score $\rightarrow$} & Low \\
\cline { 2 - 5 } & 4 & 3 & 2 & 1 \\
\hline $\begin{array}{l}\text { Photobacterium luminescence inhibition } \\
\text { test, EQC }\end{array}$ & $>100$ & $10-100$ & $1-10$ & $<1$ \\
\hline $\begin{array}{l}\text { SOS/umu genotoxicity test, } \\
\text { EQC }_{4-\mathrm{NQO}} / \mathrm{PNEC}_{4-\mathrm{NQO}}\end{array}$ & $>100$ & $10-100$ & $1-10$ & $<1$ \\
\hline $\begin{array}{l}\text { Two-hybrid yeast endocrine disrupting } \\
\text { effect test, } \mathrm{EQC}_{\mathrm{E} 2}, \mathrm{PNEC}_{\mathrm{E} 2}\end{array}$ & $>100$ & $10-100$ & $1-10$ & $<1$ \\
\hline
\end{tabular}

Fig. 2 - Toxicity score index and its valuing method ( $\mathrm{PNEC}_{\mathrm{Hg}}^{2+}$ means the predicted no-effect concentration of positive reference substance $\mathrm{Hg}^{2+}$ in Photobacterium luminescence inhibition test; PNEC 4 -NQo means the predicted no-effect concentration of positive reference substance 4-NQO in SOS/umu genotoxicity test; PNEC $_{\mathrm{E}_{2}}$ means the predicted no-effect concentration of positive reference substance E2 in two-hybrid yeast endocrine disrupting effect test). 


\subsection{Proposal and determination of toxicity rank}

For each reclaimed water sample, three toxicity scores could be obtained for respective biological effects of reclaimed water. However, for easily and vividly understanding the integrated safety of reclaimed water, a novel assessment index "toxicity rank" (TR) was proposed by integrating three toxicity scores. The index TR includes A, B, C and D four ranks, and the water quality of reclaimed water could be ranked according to the flow chart shown in Fig. 3. Among the three toxicity scores, if the worst toxicity score(s) is 4 , the TR is assigned as D. If the worst toxicity score(s) is 3, the TR is assigned as C. If the worst toxicity score(s) is 2, the TR is assigned as B. If all of three toxicity scores are 1 , the TR is assigned as A. Rank A indicates the safest water quality, while rank $\mathrm{D}$ indicates the worst water quality in view of aquatic living organism protection. For vividly describing the toxicity characteristics of reclaimed water, a triangle figure was designed as shown in Fig. 3. In addition, four colors blue, yellow, orange and red were respectively assigned for A, B, C and D ranks, to warn the safety of reclaimed water. The surrounded area with three toxicity scores in the triangle figure was colored according to the worst toxicity score as well.

\section{Case study}

In order to demonstrate the efficiency of the proposed safety assessment method for reclaimed water, samples were collected from an artificial park (named as SOF Park) in northern China. The water body of main lake (ca. $70 \mathrm{ha}$ ) in the SOF Park is supplemented by reclaimed water uniquely from a nearby wastewater reclamation treatment plant. The inlet of reclaimed water is divided into two parts, one part enters artificial wetland system for removing excessive nutrient elements and some toxic chemicals remained in reclaimed water, and the other part flows through a flower terrace with water falling for aeration. The two parts of reclaimed water enter into an oxidation pond system for further treatment, pass through mixed function zone (oxidation pond) and finally enter into the main lake. The flow direction and circulation of reclaimed water in the SOF Park are shown in Fig. 4. Six of sampling sites were distributed the inlet of reclaimed water for the SOF Park (site A), downstream of water falling through flower terrace (site B), outlet of artificial wetland system (site C), middle of oxidation pond system (site D), inlet of main lake (site E), and outlet of the main lake for water system circulating (site F). Two liters of reclaimed water sample was collected at each site on June 6, 2013. The water samples were concentrated and three toxicity tests were conducted according to the methods mentioned above. The toxicity scores and toxicity ranks of reclaimed water samples are shown in Fig. 4.

It can be seen that the quality of reclaimed water had a significant improvement along the ecological reclamation treatment processes designed in the SOF Park. The TR of reclaimed water sample at site $A$ was ranked as $C$, implying that the reclaimed water had some certain risk to aquatic organisms if directly reused as scenic and recreational water in the park. When the reclaimed water falls through the flower terrace, equaling to an aerating treatment, some of volatile compounds might be removed and the TR for sample from the site B improved to B rank. What should be emphasized was that the artificial wetland system and oxidation pond system, which appeared high treatment capability on removing toxic compounds in reclaimed water. After treating with artificial wetland system, the TR of reclaimed water sample improved from rank $C$ to rank B, and further improved to rank A after oxidation pond treatment. Subsequently, the TR of water sample collected at the inlet and outlet of main lake kept good water quality that all of them ranked as $\mathrm{A}$, which indicated that the reclaimed water in the main lake was safe for aquatic organisms.

\section{Conclusions}

Considering the various biological effects of residual chemicals in reclaimed water, three toxicity tests for different endpoints, including lethality, genotoxicity and endocrine disrupting, were
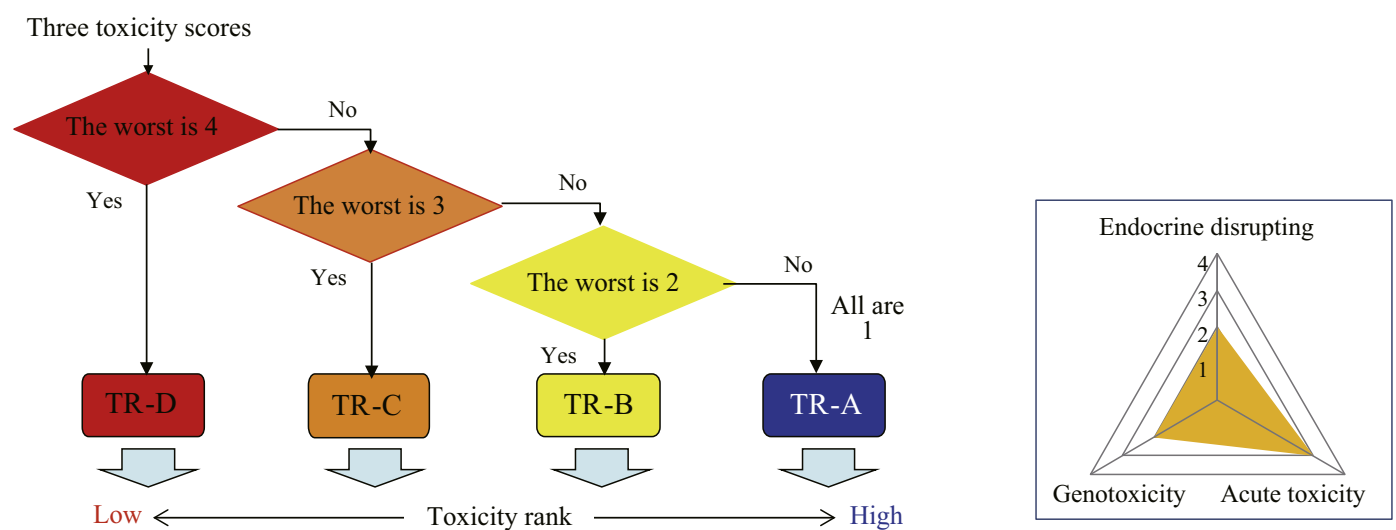

Fig. 3 - Toxicity rank (TR) index and its valuing method (TR-A means the toxicity rank A, TR-B means the toxicity rank B, TR-C means the toxicity rank C, TR-D means the toxicity rank D). 


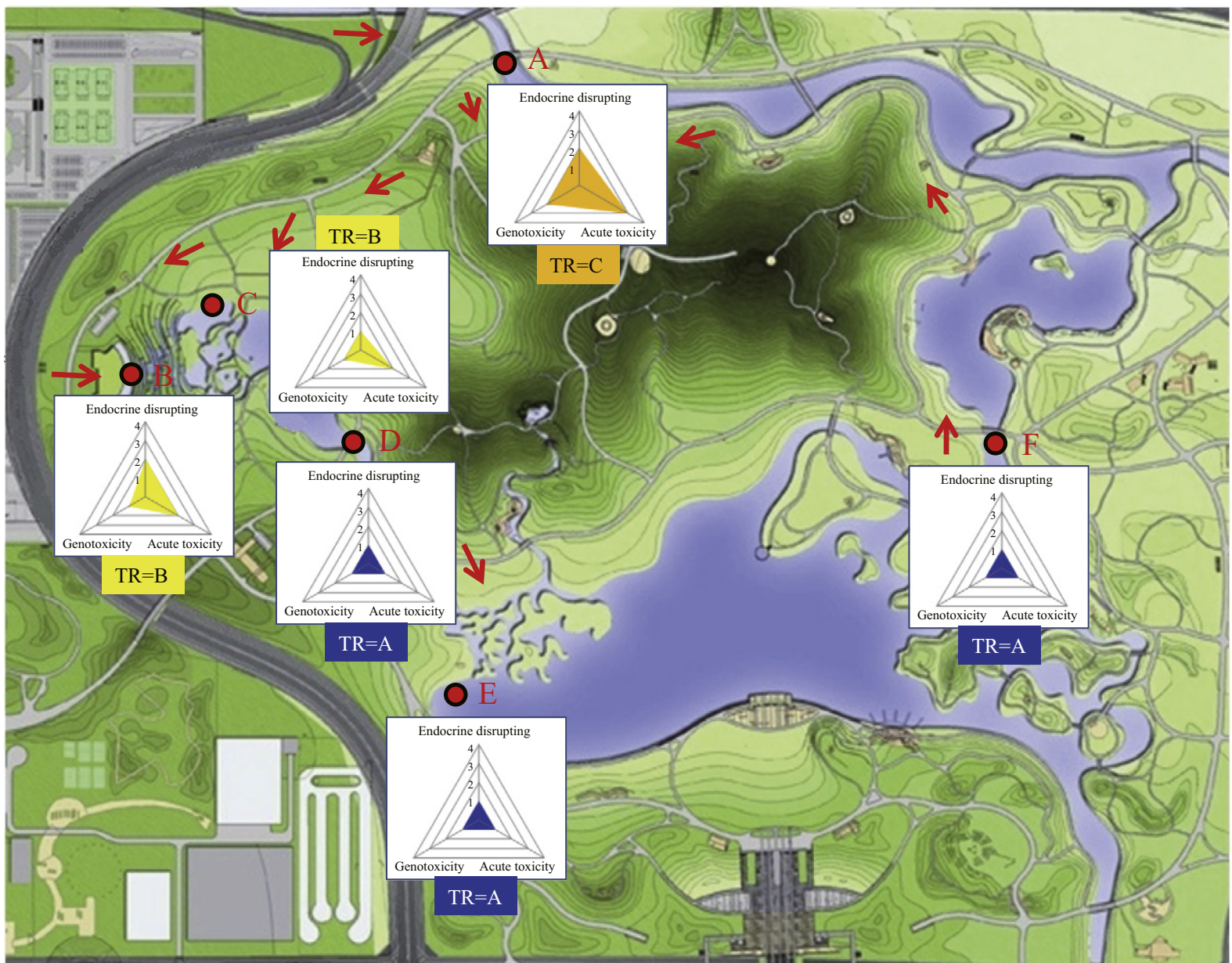

Fig. 4 - Sampling sites, toxicity scores and toxicity ranks (TRs) for the water samples collected in SOF Park (TR = A means toxicity rank A, TR = B means toxicity rank B, TR = C means toxicity rank C. Points A to F represent the six sampling sites in the SOF Park).

chosen as toxicity test battery to measure the multiple biological effects of reclaimed water. A new evaluating method based on toxicity tests was proposed to rank the quality of reclaimed water. Firstly, the tested toxicity effects of reclaimed water were converted into the equivalent concentrations of corresponding positive reference substances. Secondly, a new index "toxicity score" including 1, 2, 3 or 4 was proposed, which was valued according to the ratio of corresponding equivalent concentration to the predicted no-effect concentration. Thirdly, an integrated index toxicity rank including A, B, C, and D four ranks was proposed to evaluate the safety of reclaimed water, which was assigned according to the worst of toxicity scores. Fourthly, the case study demonstrated that the proposed method was effective to screen and rank the quality of reclaimed water. As for the reuse in the SOF Park, the direct effluent of wastewater reclamation treatment plant should have a further reclamation treatment, and the designed ecological reclamation system in the SOF Park plays an important role in guaranteeing the safety of reclaimed water. We anticipate that the present study could provide a new approach to evaluate the safety of reclaimed water for environmental reuses. Of course, since the chemical components of reclaimed water are very complex, even with the three toxicity assays mentioned in this study, it may be not enough to describe the complete biological effects of reclaimed water. More of sensitive toxicity tests should be developed and used in safety assessment of reclaimed water.

\section{Acknowledgments}

This work was supported by the National Key Technologies Research and Development Program of China (No. 2012BAJ24 B01), and the National High Technology Research and Development Program (863) of China (No. 2013AA0652051).

\section{R E F E R E N C E S}

Aldenberg, T., Jaworska, J.S., 2000. Uncertainty of the hazardous concentration and fraction affected for normal species sensitivity distributions. Ecotoxicol. Environ. Saf. 46 (1), 1-18.

Asano, T., Burton, F.L., Leverenz, H.L., Tsuchihashi, R., Tchobanoglous, G., 2007. Water Reuse-Issues, Technologies, and Applications. McGraw-Hill, New York (1-1570).

Auriol, M., Filali-Meknassi, Y., Tyagi, R.D., Adams, C.D., Surampalli, R.Y., 2006. Endocrine disrupting compounds removal from wastewater, a new challenge. Process Biochem. 41 (3), 525-539. 
Békaert, C., Rast, C., Ferrier, V., Bispo, A., Jourdain, M.J., Vasseur, P., 1999. Use of in vitro (Ames and Mutatox tests) and in vivo (Amphibian micronucleus test) assays to assess the genotoxicity of leachates from a contaminated soil. Org. Geochem. 30 (8), 953-962.

Bispo, A., Jourdain, M.J., Jauzein, M., 1999. Toxicity and genotoxicity of industrial soils polluted by polycyclic aromatic hydrocarbons (PAHs). Org. Geochem. 30 (8), 947-952.

Blaise, C., Ferard, J.F., 2005. Effluent assessment with the PEEP (potential ecotoxic effects probe) index. In: Blaise, C., Férard, J. F. (Eds.), Small-scale Freshwater Toxicity Investigations, Vol. 2 Hazard Assessment Schemes. Springer, the Netherlands.

Chang, H., Wu, S.M., Hu, J.Y., Asami, M., Kunikane, S., 2008. Trace analysis of androgens and progestogens in environmental waters by ultra-performance liquid chromatography-electrospray tandem mass spectrometry. J. Chromatogr. A 1195 (1-2), 44-51.

Chapman, P.M., Fairbrother, A., Brown, D., 1998. A critical evaluation of safety (uncertainty) factors for ecological risk assessment. Environ. Toxicol. Chem. 17 (1), 99-108.

EC (European Commission), 2003. Technical guidance document in support of Commission Directive 93/67/EEC on risk assessment for new notified substances. Commission Regulation (EC) No 1488/94 on Risk Assessment for Existing Substances and Directive 98/8/EC of the European Parliament and of the Council Concerning the Placing of Biocidal Products on the Market, Part II. European Chemicals Bureau, Ispra, pp. 1-337.

ECETOC (European Center for Ecotoxicology and Toxicology of Chemicals), 1993. Environmental Hazard Assessment of Substances. ECETOC-Technical Report No. 51. ECETOC, Brusselspp. 1-92.

EEC, 1993. Council Directive 93/67/EEC of 20 July 1993 laying down the principles for assessment of risks to man and the environment of substances notified in accordance with Council Directive 67/548/EEC. Off. J. Eur. Communities 227, 9-18.

Férard, J.F., Ferrari, B., 2005. Wastoxhas: a bioanalytical strategy for solid wastes assessment: a review. In: Blaise, C., Ferard, J.F. (Eds.), Small-scale Freshwater Toxicity Investigations: Volume 2-Hazard Assessment Schemes. Springer, New Jersey, pp. 331-375.

Hernándo, M.D., Fernández-Alba, A.R., Tauler, R., Barceló, D., 2005. Toxicity assays applied to wastewater treatment. Talanta 65 (2), 358-366.

Huber, M.M., Ternes, T.A., von Gunten, U., 2004. Removal of estrogenic activity and formation of oxidation products during ozonation of 17 alpha-ethinylestradiol. Environ. Sci. Technol. 38 (19), 5177-5186

ISO (International Organisation for Standardization), 2000. Water Quality-determination of the Genotoxicity of Water and Waste Water Using the umu-test (ISO 13829). ISO, Geneva (1-18).

Jin, H.J., Yang, X., Yin, D.Q., Yu, H.X., 1999. A case study on identifying the toxicant in effluent discharged from a chemical plant. Mar. Pollut. Bull. 39 (1-12), 122-125.

Juvonen, R., Martikainen, E., Schultz, E., Joutti, A., Ahtiainen, J., Lehtokari, M., 2000. A battery of toxicity tests as indicators of decontamination in composting oily waste. Ecotoxicol. Environ. Saf. 47 (2), 156-166.

Kimerle, R., Barnthouse, L., Brown, R., de Beyssac, B.C., Gilbertson, M., Monk, K., 1997. Ecological effects (chapter 4). In: Swanson, M.B., Socha, A.C. (Eds.), Chemical Ranking and Scoring-Guidelines for Relative Assessments of Chemical: Proceedings of the Pellston Workshop on Chemical Ranking and Scoring. SETAC Press, Florida, pp. 1-154.

Krebs, F., 2005. The pT-method as a hazard assessment scheme for wastewaters. In: Blaise, C., Férard, J.F. (Eds.), Small-scale Freshwater Toxicity Investigations, Vol. 2 Hazard Assessment Schemes. Springer, the Netherlands, pp. 115-137.
Li, M., Wei, D.B., Zhao, H.M., Du, Y.G., 2014. Genotoxicity of quinolones: substituents contribution and transformation products QSAR evaluation using 2D and 3D models. Chemosphere 95, 220-226.

Liu, R., Kameya, T., Sawai, A., Urano, K., 2007. Application of a larval medaka assay to evaluate the fish safety level in Sagami River, Japan. Environ. Monit. Assess. 130 (1-3), 475-482.

Ma, M., Rao, K.F., Wang, Z.J., 2007. Occurrence of estrogenic effects in sewage and industrial wastewaters in Beijing, China. Environ. Pollut. 147 (2), 331-336.

Mantis, I., Voutsa, D., Samara, C., 2005. Assessment of the environmental hazard from municipal and industrial wastewater treatment sludge by employing chemical and biological methods. Ecotoxicol. Environ. Saf. 62 (3), 397-407.

Mathur, N., Bhatnagar, P., Mohan, K., Bakre, P., Nagar, P., Bijarnia, M., 2007. Mutagenicity evaluation of industrial sludge from common effluent treatment plant. Chemosphere 67 (6), 1229-1235.

Matsui, S., Takigami, H., Matsuda, T., Taniguchi, N., Adachi, J., Kawami, H., et al., 2000. Estrogen and estrogen mimics contamination in water and the role of sewage treatment. Water Sci. Technol. 42 (12), 173-179.

Michael, I., Rizzo, L., McArdell, C.S., Manaia, C.M., Merlin, C., Schwartz, T., et al., 2013. Urban wastewater treatment plants as hotspots for the release of antibiotics in the environment: a review. Water Res. 47 (3), 957-995.

Munn, M.D., Gilliom, R.J., 2001. Water-resources investigations report 01-4077: pesticide toxicity index for freshwater aquatic organisms. United States Geological Survey (USGS), California, 1-61.

Nakahara, W., Fukuoka, F., Sugimara, T., 1957. Carcinogenic action of 4-nitroquinoline-N-oxide. Gann 48 (2), 129-137.

Oda, Y., Nakamura, S.I., Oki, I., Kato, T., Shinagawa, H., 1985. Evaluation of the new system (umu-test) for the detection of environmental mutagens and carcinogens. Mutat. Res. 147 (5), 219-229.

OECD, 2012. OECD Guideline for the Testing of Chemicals, TG-455: Performance-based Test Guideline for Stably Transfected Transactivation In Vitro Assays to Detect Estrogen Receptor Agonists. OECD, Paris (1-39).

Personne, G., Marsalek, B., Blinova, I., Torokne, A., Zarine, D., Manusadzianas, L., et al., 2003. A practical and user-friendly toxicity classification system with microbiotests for natural waters and wastewaters. Environ. Toxicol. 18 (6), 395-402.

Posthuma, L., Suter II, G.W., Traas, T.P., 2002. Species Sensitivity Distributions in Ecotoxicology. CRC Press LLC, Boca Raton (1-616).

Quirós, L., Céspedes, R., Lacorte, S., Viana, P., Raldúa, D., Barceló, D., et al., 2005. Detection and evaluation of endocrine-disruption activity in water samples from Portuguese rivers. Environ. Toxicol. Chem. 24 (2), 389-395.

Rehmann, K., Schramm, K.W., Kettrup, A.A., 1999. Applicability of a yeast oestrogen screen for the detection of oestrogen-like activities in environmental samples. Chemosphere 38 (14), 3303-3312.

Rutishauser, B.V., Pesonen, M., Escher, B.I., Ackermann, G.E., Aerni, H.R., Suter, M.J.F., et al., 2004. Comparative analysis of estrogenic activity in sewage treatment plant effluents involving three in vitro assays and chemical analysis of steroids. Environ. Toxicol. Chem. 23 (4), 857-864.

Sato, T., Chickazawa, K., Yamamori, H., Ose, Y., Nagase, H., Kito, H., 1991. Evaluation of the SOS chromotest for the detection of antimutagens. Environ. Mol. Mutagen. 17 (4), 258-263.

Schuler, L.J., Hoang, T.C., Rand, G.M., 2008. Aquatic risk assessment of copper in freshwater and saltwater ecosystems of South Florida. Ecotoxicology 17 (7), 642-659.

SEPA (State Environmental Protection Administration), 1995. Water Quality-Determination of the Acute Toxicity—Luminescent Bacteria Test (GB/T15441-1995). SEPA, Beijing, pp. 1-7. 
Sijm, D., De Bruijn, J., Crommentuijn, T., Van Leeuwen, K., 2001. Environmental quality standards: endpoints or triggers for a tiered ecological effect assessment approach. Environ. Toxicol. Chem. 20 (11), 2644-2648.

Steidler, N.E., Reade, P.C., 1984. Experimental induction of oral squamous cell carcinomas in mice with 4-nitroquinoline-1-oxide. Oral Surg. Oral Med. Oral Pathol. 57 (5), 524-531.

Sun, Q.F., Deng, S.B., Huang, J., Shen, G., Yu, G., 2008. Contributors to estrogenic activity in wastewater from a large wastewater treatment plant in Beijing, China. Environ. Toxicol. Pharmacol. 25 (1), 20-26.

Svenson, A., Allard, A.S., Ek, M., 2003. Removal of estrogenicity in Swedish municipal sewage treatment plants. Water Res. 37 (18), 4433-4443.

Tilton, F., Benson, W.H., Schlenk, D., 2002. Evaluation of estrogenic activity from a municipal wastewater treatment plant with predominantly domestic input. Aquat. Toxicol. 61 (3-4), 211-224.

USEPA (US Environmental Protection Agency), 1991. Technical Support Document for Water Quality-based Toxics Control (EPA/505/2-90/001). USEPA, Washington DC, pp. 1-335.

USEPA (US Environmental Protection Agency), 1996. Technical Report: Regions 9 and 10 Guidance for Implementing Whole Effluent Toxicity Testing Programs. USEPA, Seattle, pp. 1-191.

USEPA (US Environmental Protection Agency), 2002. Methods for Measuring the Acute Toxicity of Effluents and Receiving Waters to Freshwater and Marine Organisms (Fifth Edition, EPA/821/R-02/012). USEPA, Washington DC, pp. 1-275.

USEPA (US Environmental Protection Agency), 2004. Guidelines for Water Reuse (EPA/625/R-04/108). USEPA, Washington DC, pp. $1-450$.

Vindimian, E., Garric, J., Flammarion, P., Thybaud, E., Babut, M., 1999. An index of effluent aquatic toxicity designed by partial least squares regression, using acute and chronic tests and expert judgments. Environ. Toxicol. Chem. 18 (10), 2386-2391.
Wagner, C., Lokke, H., 1991. Estimation of ecotoxicological protection levels from NOEC toxicity data. Water Res. 25 (10), 1237-1242.

Wang, J.X., Wu, W.Z., Henkelmann, B., You, L., Kettrup, A., Schramm, K.W., 2003. Presence of estrogenic activity from emission of fossil fuel combustion as detected by a recombinant yeast bioassay. Atmos. Environ. 37 (23), 3225-3235

Wei, D.B., Zhai, L.H., Dong, C.H., Hu, H.Y., 2004. QSAR-based toxicity classification and prediction for single and mixed aromatic compounds. SAR QSAR Environ. Res. 15 (3), 207-216.

Wei, D.B., Kisuno, A., Kameya, T., Urano, K., 2006. A new method for evaluating biological safety of environmental water with algae, daphnia and fish toxicity ranks. Sci. Total Environ. 371 (1-3), 383-390.

Wei, D.B., Tan, Z.W., Du, Y.G., 2012. Toxicity-based assessment on treatment performance of sewage reclamation processes. J. Environ. Sci. 24 (6), 969-978.

Ying, G.G., Kookana, R.S., 2004. Simultaneous determination of imidacloprid, thiacloprid, and thiamethoxam in soil and water by high-performance liquid chromatography with diode-array detection. J. Environ. Sci. Health B 39 (5-6), 737-746.

Ying, G.G., Kookana, R.S., Ru, Y.J., 2002. Occurrence and fate of hormone steroids in the environment. Environ. Int. 28 (6), 545-551.

Zha, J.M., Wang, Z.J., 2005. Assessing technological feasibility for wastewater reclamation based on early life stage toxicity of Japanese medaka (Oryzias latipes). Agric. Ecosyst. Environ. 107 (2-3), 187-198.

Zhang, J., Zhang, Y.B., Liu, W., Quan, X., Chen, S., Zhao, H.M., et al., 2013. Evaluation of removal efficiency for acute toxicity and genotoxicity on zebrafish in anoxic-oxic process from selected municipal wastewater treatment plants. Chemosphere 90 (11), 2662-2666. 